ceptibility " to experimental infection with one source of agent is controlled by a single gene and that the dominant allele confers " susceptibility". There is evidence that scrapie agent may replicate in some " resistant " sheep but at a slower rate than in " susceptible " sheep. For this reason, "resistance" is best regarded in terms of an extended incubation period. Also, "resistance " to one strain of agent does not mean " resistance " to all strains. A " resistant" flock of Swaledale sheep is being developed by experimentally infecting all animals and breeding from the survivors. There have been extensive outbreaks of natural scrapie in the " susceptible " flocks of Cheviot and Herdwick sheep.

Investigations of these outbreaks might be able to show whether or not sheep selected for "resistance" could be used to limit the spread of infection in flocks with a serious scrapie problem.

\title{
RESISTANCE OF CALVES TO GASTROINTESTINAL PARASITES
}

\author{
C. C. OSTERLEE, A. KLOOSTERMAN and G. A. A. ALBERS \\ Dep. of Animal Production of the Agricultural University \\ Wageningen, Duivendaal 5, the Netherlands
}

Control of enzootic diseases is possible by hygienic measures and by increasing resistance of the animals. The resistance of calves to gastrointestinal nematodes is discussed as an example where the reaction of animals to a certain dose of infective larvae can be measured by serological as well as parasitological parameters. This resistance vary considerable in calves of the same age and feeding condition, and part of it is genetically determined. The question what this resistance means for the growth performance of the calf under various conditions of infection remains to be answered.

\section{IMMUNOGENETICS STUDIES ON CATTLE TWINS}

\author{
J. SELLEI \\ Dep. of Animal Breeding and Genetics \\ Swedish University of Agricultural Sciences, \\ $S-750$ o7 Uppsala, Sweden
}

\begin{abstract}
Some components which are essential factors in the immune mechanism were quantified (titre tested) in the sera from cattle twins. It was found that in monozygous twins the kinetics of antibody formation against red cell antigens was under close genetic control. This phenomenon indicates that not only the amount but also the start, the raise and the persistence of antibody formation is genetically controlled. These results were obtained in twins which had never before been confronted with these antigens and where the dosage and route of injection was carefully controlled. When the contact with the antigen as in the case of the ubiquitously occuring $\mathrm{J}$ substance could not be controlled genetic variation in the anti-I antibody titres was not demonstrable. The titre tests revealed considerable genetic variation also in the relative activity of complement $\left(\overrightarrow{\mathrm{CI}}\right.$ trough $\left.\overline{\mathrm{C}_{3}}\right)$ and konglutinin in the twin sera.
\end{abstract}

\section{GENETIC ANALYSIS OF HEALTH DISTURBANCES IN PIGS}

\section{N. LUNDEHEIM}

(Sweden)

Since the beginning of 1973 every pig from the Swedish Pig progeny testing stations pass a special post-mortem examination where any disease in the thoracic cavity or in the snout is registered. The diseases which are thereby recorded are different kinds of pneumonia, pleurisy and atrophic thinitis (AR).

Data from this post-mortem examination during 1973-1975 were merged with the ordinary progeny testing records. This merging could not be done for those animals or groups which for 
some reason had been excluded from the testing. After this merging exactly io ooo individuals remained.

The disease records and certain production traits have been analysed statistically, whereby the health registrations were regarded as all-or-rone traits $(0=$ healthy, $\mathbf{I}=$ sick $)$, i.e. the degree of affection is disregarded.

The results from these analyses shows that Landrace pigs seems to have far fewer lung lesions than Yorkshire, whereas the relation for AR is with weak significance the reverse. The sex differences indicate that castrates are somewhat more susceptible to the infectious diseases thati gilts are.

The heritability estimates for the diseases, considered as all-or-none traits lie between 0.12 and o.I4.

The phenotypic correlations between lung- and snout lesions and production traits show that generally speaking a disease pig grows more slowly, is leaner, has a smaller $M$. Longissimus dorsi area and has rather more meat in the side, compared with healty animals. Genetic correlations between respiratory diseases and productions traits fail to display any significance.

Genetic Resistance, OF PIGS TO NEONATAL, ENTERITIS CAUSED by E. Coli

\author{
R. A. GIBBONS and R. SELLWOOD \\ A.R.C. Institute for Research on Animal Diseases, \\ Compton, Nerebury, Berkshive, U.K.
}

The strains of $E$. coli which are usually associated with neonatal diarrhoea in the piglet possess the K88 antigen. This antigen is a virulence determinant and it functions as such by adhering the organisms to the intestine of the piglet. In some pigs the gut cell receptor for $\mathrm{K} 88$ is absent, K88 positive organisms do not attach themselves to the intestinal wall of these pigs which animals are therefore almost wholly resistant to the disease. Resistance is inherited as a simple autosomal recessive designated $s$; the dominant allele $\mathrm{S}$ conferring adhesiveness and disease susceptibility on the animal.

In spite of the advantage conferred upon the homozygous recessive ss neonate, allele $\mathrm{S}$ seems common, indeed predominant. The probable reason for this paradox lies in the relative failure of $s s$ sows to respond immunologically to the K88 positive E. coli in the gut. This causes heterozygous piglets out of homozygous recessive sows to be at a large disadvantage compared with all other piglets. Since $s$ is the less common allele, selection against this heterozygote tends to eliminate it. Despite the prevalence of allele $\mathrm{S}$, there is no disadvantage to $s$ unless $\mathrm{S}$ is also present in the same breeding population; the ss animal should therefore be economically valuable.

STRAIN AND FAMILY EFFECTS ON RESISTANCE OF " LEGHORN" HENS AGAINST DIFFERENT DISSAE,

\author{
W. HARTMAN, G. HEIL, D. V. D. HAGEN and H. Ch. LOELIGER \\ Institut $f$. Kleintierzucht der Bundesforschungsanstalt $f$. \\ Landwirtschaft, Braunschweig-Volkenrode, \\ $D$ - 3roo Celle, W-Germany
}

Mortality data of 3 Leghorn lines and their crosses from the years 1972, 1973 and 1975, totalling about $\mathrm{I} 2$ ooo female offsprings from more than $\mathrm{I} 50$ sires and 2000 dams were analysed. The hens were kept in the Institute for Small Animal Research at Celle under conditions of normal exposure to disease.

The investigation leads to the following results:

I) Most mortality traits were influenced by the line combinations as well as paternal-and maternal-line effects.

2) Even under conditions of normal exposure crossbreds had less mortality than purebreds.

3) For Marek Disease heritability estimated on a "liability" scale seems to be such that it is worthwhile to seek for a normally distributed alternative trait when selecting for livability. 